\title{
Aberrations of the FHIT Gene and Fhit Protein in Canine Lymphoma Cell Lines
}

\author{
Hiroko HIRAOKA $^{1)}$, Koji MINAMI ${ }^{1)}$, Naoki KANEKO ${ }^{1)}$, Takako SHIMOKAWA MIYAMA ${ }^{1)}$, Yasuhiko OKAMURA ${ }^{2)}$, \\ Takuya MIZUNO ${ }^{1)}$ and Masaru OKUDA ${ }^{1) *}$ \\ ${ }^{1)}$ Laboratory of Veterinary Internal Medicine, Faculty of Agriculture, Yamaguchi University, 1677-1 Yoshida, Yamaguchi 753-8515 and \\ ${ }^{2)}$ Laboratory of Veterinary Teaching Hospital, Faculty of Agriculture, Iwate University, 3-18-8 Ueda, Morioka, Iwate 020-8550, Japan
}

(Received 28 November 2008/Accepted 26 January 2009)

ABSTRACT. The fragile histidine triad (FHIT) gene is a tumor-associated gene, and aberrant FHIT gene and protein expression have been described in many types of human tumors. Furthermore, it has been reported that FHIT gene inactivation is induced by hypermethylation of 5' $\mathrm{CpG}$ islands in the gene or by genomic deletion around the open reading frame (ORF). In this study, we explored the aberrations in the canine FHIT gene and Fhit protein expression and assessed the methylation status and genomic deletions by using 5 canine lymphoma cell lines. We found that the decrease in the expression of the Fhit protein in canine lymphoma cell lines was similar to that in human tumors. The expression of the wild-type FHIT transcript was reduced in all 5 cell lines. However, we could not confirm the involvement of aberrant methylation events in the $5^{\prime} \mathrm{CpG}$ islands of the canine FHIT gene. We were able to identify homozygous or heterozygous deletions in the canine FHIT genes in all 5 cell lines. Moreover, a widespread genomic deletion of the FHIT gene, which included the ORF region, was detected in 1 cell line. In the present study, we detected aberrations in the FHIT gene and Fhit protein expression in all 5 canine lymphoma cell lines, and this phenomenon might be an important factor in promoting canine lymphoma. KEY WORDS: cancer, canine, DNA methylation, gene expression, lymphoma/leukemia.

J. Vet. Med. Sci. 71(6): 769-777, 2009

Common fragile sites (CFSs) are unstable genomic regions that tend to form gaps and breaks on metaphase chromosomes when the cells are exposed to replication impedance [3, 11, 28]. Among CFSs, FRA3B (3p14.2) is one of the most frequently affected regions in the human genome, and allelic loss or homozygous deletions in this region have been found in many types of cancers, including lung, renal, esophageal, breast and cervical tumors $[11,28]$. Regardless of the unstability of this region, some genes are located at FRA3B, and one such gene-the fragile histidine triad (FHIT) gene-has been extensively investigated [17, 28]. The product of this gene, Fhit protein, is considered to be a tumor-suppressor protein and a modulator of the cell cycle and apoptosis $[19,20]$.

In humans, aberrant FHIT gene expression and downregulated Fhit protein expression have been reported in many types of solid tumors, including lung, cervical, esophageal and breast tumors, and in hematopoietic malignancies, including myelocytic leukemia, lymphocytic leukemia and non-Hodgkin's lymphoma $[16,26]$. Aberrant methylation of the CpG islands around exon 1 of the FHIT gene has been reported in numerous cancers, including esophageal, lung, breast and cervical tumors, and lymphocytic leukemia [30, $33,39,40]$. Aberrant methylation is associated with inactivation of the FHIT gene, and studies on esophageal and nonsmall lung cancer cell lines have shown that demethylation of hypermethylated cells induces re-expression of the FHIT gene $[30,40]$. Furthermore, homozygous or heterozygous deletion of the FHIT/FRA3B region has been reported in

\footnotetext{
* CorRespondence to: OKudA, M., Laboratory of Veterinary Internal Medicine, Faculty of Agriculture, Yamaguchi University, Yamaguchi 753-8515, Japan.

e-mail: okudamu@yamaguchi-u.ac.jp
}

some cancer cells $[1,8,18,22,27]$. These reports have described allelic losses around exon 5 of the human FHIT gene, which is a region containing the start codon of the open reading frame (ORF) of FHIT; however, the deletion points vary between the types of cancer $[6,18]$. In some human lung cancer cell lines, homozygous deletions have been shown to be associated with loss of the wild-type FHIT transcripts and expression of an aberrant transcript [8].

Recently, we demonstrated the canine FHIT gene structure and its protein expression in peripheral blood mononuclear cells (PBMCs) and other tissues, including tissues of the lungs, intestine, liver, spleen and thymus, in healthy dogs [15]. The canine FHIT gene is located in an approximately 1.4-megabase pair ( $\mathrm{Mbp})$ region of canine chromosome 20; the wild-type transcript is composed of 9 small exons (30-306 bp) that are separated by extremely large introns (2,333-494,789 bp), and the ORF corresponds to exons 4 to 8 . Furthermore, an alternative splicing form of the FHIT transcript (named type B) has been found in PBMCs and other tissues. The 5' noncoding region of the type-B transcript was differentiated from the wild-type transcript by the presence of a novel exon-exon 3B-that was present in the region between exons 3 to 4 of the wild-type transcript. However, the type-B transcript shows the same exons as the wild-type FHIT transcript after exon 4; therefore, the type-B transcript does not induce any aberrant expression of the Fhit protein in dog PBMCs. In dogs, many types of tumors develop in the same manner as they do in humans. However, to the best of our knowledge, the relationship between the canine FHIT gene and tumor development in dogs has not been explored. In this study, we focused on canine lymphoma, which is one of the most common tumors in dogs. Canine lymphoma accounts for 
approximately $7 \%-24 \%$ of all canine tumors and $83 \%$ of all canine hematopoietic malignancies [32], and the inactivation of p16 cyclin-dependent kinase inhibitor has recently been shown to be associated with tumorigenesis in canine lymphoma [9]. However, the precise molecular mechanisms of tumorigenesis in cases of canine lymphoma remain to be elucidated. Clarification of the correlation between canine lymphoma and the aberrations of the FHIT gene and Fhit protein expression may be helpful in analysis of cancer etiology in the veterinary field. Therefore, we examined the aberrations of the FHIT gene and Fhit protein expression by using canine lymphoma cell lines. Furthermore, we explored the hypermethylation of 5' $\mathrm{CpG}$ islands and the effects of FHIT allelic deletion.

\section{MATERIALS AND METHODS}

Cells: In this study, we used 2 newly established canine lymphoma cell lines (the Ema line and the Nody-1 line) and 3 previously reported canine lymphoma cell lines (CL-1, UL-1 and GL-1) [23, 24, 35]. The Ema and Nody-1 lines were established from the pleural effusion of a patient with thymic lymphoma and the ascites fluid of a patient with alimentary lymphoma, respectively; the T cell lineages of the 2 cell lines were confirmed by $\mathrm{T}$ cell-receptor gene rearrangement analysis and surface-antigen analysis using a flow cytometer. All the cell lines were maintained in a complete medium [RPMI-1640 containing 10\% fetal bovine serum (FBS), penicillin $(100 \mathrm{U} / \mathrm{m} l)$ and streptomycin $(100$ $\mu \mathrm{g} / \mathrm{m} l)]$ and grown in an atmosphere containing $5 \% \mathrm{CO}_{2}$. PBMCs were obtained from a healthy beagle dog. Briefly, the heparinized whole blood was centrifuged, and the buffy coat was suspended in phosphate-buffered saline (PBS; 2.7 $\mathrm{mM} \mathrm{KCl}, 0.14 \mathrm{M} \mathrm{NaCl}, 1.5 \mathrm{mM} \mathrm{KH}_{2} \mathrm{PO}_{4}, 8.1 \mathrm{mM}$ $\mathrm{Na}_{2} \mathrm{HPO}_{4} \cdot 12 \mathrm{H}_{2} \mathrm{O}$ ). PBMCs were isolated by gradient centrifugation using Lymphoprep (Fresenius Kabi Norge, Oslo, Norway) and further purified by overlaying them on FBS and performing centrifugation to remove contaminated platelets. The cells were cultured in the complete medium for $2 \mathrm{hr}$ to remove monocytes. Microscopic analysis was performed, and approximately $80 \%$ of the cells were confirmed to be lymphocytes; these cells were used as the control throughout the present study.

$R N A$ extraction, reverse transcriptase-polymerase chain reaction (RT-PCR) and sequence analysis: Total RNA was extracted by using TRI Reagent (Molecular Research Center, Cincinnati, OH, U.S.A.), and single-strand cDNA was synthesized from $2.5 \mu \mathrm{g}$ of each total RNA sample by using SuperScript II RT (Invitrogen, Carlsbad, CA, U.S.A.) with an oligo-dT primer in accordance with the manufacturer's instructions. We prepared 3 primer pairs-e1/eL, BF1/eL and TF5/TF3 (Table 1)-to detect the canine FHIT genes; in our previous study, we had confirmed that these 3 primer pairs amplify the canine FHIT gene transcripts [15]. These primer pairs were used to amplify exons 1 to 9 of the canine wild-type FHIT transcript, exons $3 \mathrm{~B}$ to 9 of the alternative splicing form (type B), and exons 4 to 8 of the common ORF of these transcripts (Fig. 1A). The canine ribosomal protein L32 (RPL32), which is a stable housekeeping gene in canine lymphatic cells and tissues, was amplified as a control (Table 1) [25]. A thermal GeneAmp PCR system 9700 (Applied Biosystems, Foster, CA, U.S.A.) was used for PCR amplification, which was performed by using the following protocol: denaturation at $95^{\circ} \mathrm{C}$ for $5 \mathrm{~min} ; 35$ cycles of $94^{\circ} \mathrm{C}$ for $1 \mathrm{~min}, 58-65^{\circ} \mathrm{C}$ for $1 \mathrm{~min}$ and $72^{\circ} \mathrm{C}$ for $2 \mathrm{~min}$; and then a final incubation at $72^{\circ} \mathrm{C}$ for $10 \mathrm{~min}$. The PCR products were electrophoresed on $1.5 \%$ agarose gels and stained with ethidium bromide. The amplified products were further analyzed by direct sequencing using a BigDye Terminator v3.0 Ready Reaction Cycle Sequencing kit (Applied Biosystems); further analysis was performed at the DNA Core facility of the Center for Gene Research, Yamaguchi University.

Immunoblot analysis: Immunoblot analysis was performed by using a rabbit antihuman Fhit polyclonal antibody (clone ZR44; Invitrogen) that had been confirmed to detect the canine Fhit protein in a previous study [15]. Each sample was lysed in NP-40 lysis buffer [1\% NP-40, $50 \mathrm{mM}$ Tris ( $\mathrm{pH} 8.0), 150 \mathrm{mM} \mathrm{NaCl}, 1 \% \mathrm{SDS}, 2 \mu \mathrm{g} / \mathrm{m} l$ leupeptin and $2 \mu \mathrm{g} / \mathrm{m} l$ aprotinin] and was sonicated to degrade the genomic DNA. The lysates were cleared by centrifugation at $15,000 \mathrm{rpm}$ for $10 \mathrm{~min}$ at $4^{\circ} \mathrm{C}$. The lysates $(50 \mu \mathrm{g}$ per sample) were diluted with SDS sample buffer [2\% SDS, $10 \%$ glycerol, $60 \mathrm{mM}$ Tris (pH 6.8), $5 \% \beta$-mercaptoethanol, $0.01 \%$ bromophenol blue], separated by using $15 \%$ SDSpolyacrylamide gel electrophoresis (PAGE) and blotted onto a nitrocellulose membrane. The membrane was incubated in a blocking buffer consisting of $5 \%(\mathrm{wt} / \mathrm{vol})$ nonfat dry milk in Tris-buffered saline containing Tween 20 (TBST) $[20 \mathrm{mM}$ Tris- $\mathrm{HCl}(\mathrm{pH} 7.4)$ and $150 \mathrm{mM} \mathrm{NaCl}$ containing $0.05 \%$ Tween 20] for $1 \mathrm{hr}$, incubated with the antihuman Fhit antibody (diluted 1:500 in TBS-T) for $1 \mathrm{hr}$ at room temperature, rinsed with TBS-T and incubated with horseradish peroxidase-conjugated goat antirabbit IgG (Invitrogen; diluted 1:4000 in TBS-T) for $1 \mathrm{hr}$ at room temperature. The antibody-antigen complex was washed with TBS-T and visualized by using a Western Lightning Chemiluminescence Reagent Plus kit (PerkinElmer, Waltham, MA, U.S.A.) and an LAS-3000mini chemiluminescence detection system (Fujifilm, Tokyo, Japan). The membrane was reprobed with an antihuman actin polyclonal antibody (clone C-11; Santa Cruz Biotechnology, Santa Cruz, CA, U.S.A.).

Bisulfite modification of DNA and methylation specific$P C R$ (MS-PCR): MS-PCR was performed to assess the methylation status in the canine lymphoma cell lines. The $\mathrm{CpG}$ sites of the canine FHIT gene were determined by using the human FHIT CpG site map [30] to examine the region around exon 1 of the FHIT genomic sequence, and 3 primer pairs were designed by using the Methyl Primer Express software ver.1.0 (Applied Biosystems). The primer pairs $\mathrm{MpF} 1 / \mathrm{MpR} 1$ and $\mathrm{UpF} 1 / \mathrm{UpR} 1$ were used to amplify methylated FHIT DNA and unmethylated FHIT DNA, respectively (Table 1). The third primer pair-WpF1/ 
WpR1-was used to amplify the control, wild-type FHIT DNA, which had not undergone bisulfite modification. The DNA samples were extracted by using a QIAamp DNA Mini kit (QIAGEN, Hilden, Germany), and $1 \mu \mathrm{g}$ of each DNA sample was used as the template for bisulfite modification, which was performed by using a CpGenome DNA Modification kit (Chemicon International, Temecula, CA, U.S.A.) in accordance with the manufacturer's instructions. We used a HotStarTaq master mix kit (QIAGEN) and $50 \mathrm{ng}$ of each DNA sample for PCR amplification. The following conditions were employed for PCR amplification: $95^{\circ} \mathrm{C}$ for $15 \mathrm{~min} ; 35$ cycles of $94^{\circ} \mathrm{C}$ for $30 \mathrm{sec}, 55-65^{\circ} \mathrm{C}$ for $30 \mathrm{sec}$ and $72^{\circ} \mathrm{C}$ for $1 \mathrm{~min}$; and then $72^{\circ} \mathrm{C}$ for $10 \mathrm{~min}$. The amplified products were electrophoresed on $2 \%$ agarose gels and stained with ethidium bromide.

Deletion analysis: In order to identify the deletions in the canine FHIT genomic locus in the cell lines, we designed 20 pairs of primers corresponding to the intronic region between exon 3 and the type-B-specific exon $3 \mathrm{~B}(1 \mathrm{~F} / \mathrm{R}-6 \mathrm{~F} /$ $\mathrm{R})$, exons $3 \mathrm{~B}$ and $4(7 \mathrm{~F} / \mathrm{R}-12 \mathrm{~F} / \mathrm{R})$ and exons 4 and $5(13 \mathrm{~F} /$ $\mathrm{R}-20 \mathrm{~F} / \mathrm{R}$; Table 1). These primers were designed to amplify $800-1,000$ bp products, which were randomly selected within each intronic region. The DNA samples were prepared as described above, and PCR amplification was performed by using a HotStarTaq master mix kit (QIAGEN). The following conditions were employed for PCR analysis: $95^{\circ} \mathrm{C}$ for $15 \mathrm{~min} ; 35$ cycles of denaturation at $94^{\circ} \mathrm{C}$ for $30 \mathrm{sec}$, annealing at $58^{\circ} \mathrm{C}$ for $30 \mathrm{sec}$ and extension at $72^{\circ} \mathrm{C}$ for $2 \mathrm{~min}$. The amplified products were electrophoresed on $2 \%$ agarose gels and visualized by using ethidium bromide staining.

\section{RESULTS}

Expression of FHIT transcripts in canine lymphoma cell lines: We explored the expression pattern of the FHIT gene transcripts in canine lymphoma cell lines by using specific primers to perform RT-PCR amplifications of the wild-type, type B and ORF transcripts of canine FHIT. The expected 872-bp product of the wild-type transcript band was observed in the case of the control PBMCs [Fig. 1B (a)]. Furthermore, we observed a faint band in the case of the UL1 and GL-1 cell lines, but we did not detect any transcript in the case of the Ema and Nody-1 cell lines. In the case of CL-1, we detected a smear and 2 small transcripts with lengths of $500 \mathrm{bp}$ and $600 \mathrm{bp}$ [Fig. 1B (a)]. Direct sequence analysis showed that the amplified transcripts in the UL-1 and GL-1 cell lines showed $100 \%$ similarity with the wildtype FHIT transcript. We used the e1/eL primer pair to analyze the transcripts from CL-1; however, we were unable to identify the sequences of the smear or the 2 small-sized transcripts. The type-B transcript could not be amplified from any of the cell lines [Fig. 1B (b)]. The expression of the ORF region seemed to be reduced in all the cell lines, especially in the Ema and Nody-1 cell lines, and no bands were detected in the CL-1 cell line [Fig. 1B (c)]. Sequence analysis of the ORF in the Ema and Nody-1 cell lines showed
A

(a)

(b)
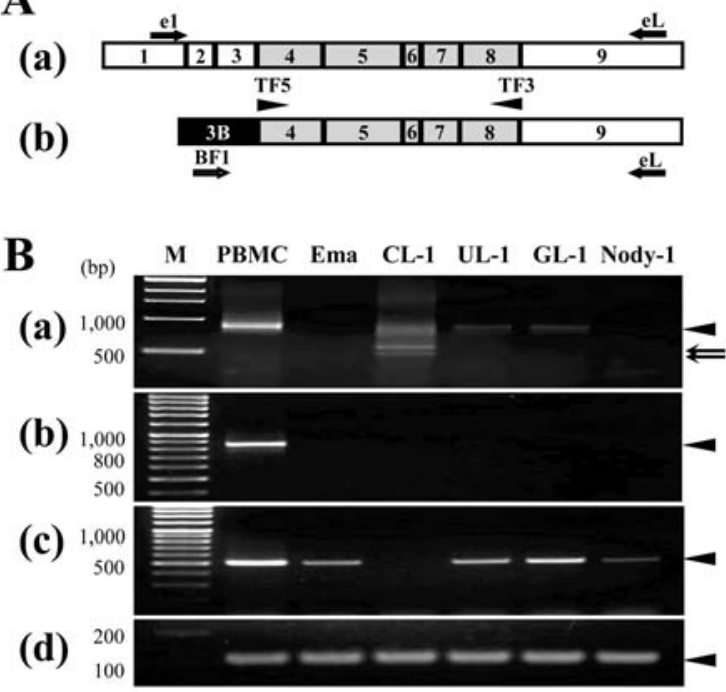

C PBMC Ema CL-1 UL-1 GL-1 Nody-1

(a)

(b)

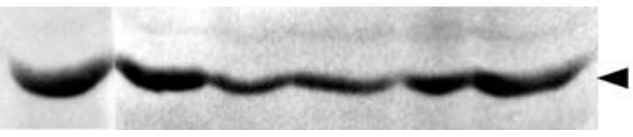

Fig. 1. A. The 2 types of canine FHIT transcripts. (a) The wild-type canine FHIT transcript is composed of 9 exons and is amplified by the primers e1/eL (black arrows). (b) The alternative splicing form of the canine FHIT transcript (Type $\mathrm{B}$ ) has a unique 5 ' non-coding sequence, exon $3 \mathrm{~B}$, and is amplified by primers BF1/eL (white and black arrows, respectively). These 2 types of transcripts share the same ORF, which corresponds to exons 4-8 (shaded boxes), and the TF5/TF3 primer pair (arrowheads) amplifies this region. B. RT-PCR analysis of the FHIT gene transcripts in the canine lymphoma cell lines. Expression of the wild-type FHIT transcript (a), the type-B transcript (b) and the ORF region (c) was determined by RT-PCR. The canine ribosomal protein L32 (RPL32) was amplified as an internal control (d). The arrowheads indicate the expected bands, and arrows indicate the unexpected bands observed in the CL-1 cell line. C. Immunoblot analysis for detection of Fhit protein in the canine lymphoma cell lines. The expression of canine Fhit protein was detected using an antihuman Fhit polyclonal antibody (clone ZR44; Invitrogen) (a). As a control, an antihuman actin polyclonal antibody (clone C-11; Santa Cruz Biotechnology) was used to reprobe the membrane (b).

that these 2 cell lines had sequences that were the same as that obtained from the wild-type transcript.

Expression of the Fhit protein in canine lymphoma cell lines: In our previous study, a rabbit antihuman Fhit polyclonal antibody (clone ZR44, Invitrogen) was used to detect the canine Fhit protein (approximately $17 \mathrm{kDa}$ ) in the PBMCs of healthy dogs [15]. We performed immunoblot 
Table 1. Oligonucleotide primers for PCR amplification

\begin{tabular}{|c|c|}
\hline Primers & Sequences $\left(5^{\prime}-3^{\prime}\right)$ \\
\hline \multicolumn{2}{|c|}{ FHIT transcripts detection primers } \\
\hline e1 & TCACTTCCCAGCTGCCAAGATC \\
\hline $\mathrm{eL}$ & TAAGTACATAGCCCAGGAAGTGTGGAAG \\
\hline $\mathrm{BF} 1$ & CTGTGGACAGAAACATCCCACCTG \\
\hline $\mathrm{TF} / \mathrm{TF}^{\mathrm{a})}$ & TAGGATCCGCTTCAACCGTGAGGAAATG/ ACGATATCTTTCATGCCTGTAAAGTCA \\
\hline RPL32-F/ RPL32-R & TGGTTACAGGAGCAACAAGAAA/ GCACATCAGCAGCACTTCA \\
\hline \multicolumn{2}{|l|}{ MS-PCR primer pairs } \\
\hline $\mathrm{MpF} 1 / \mathrm{MpR} 1$ & GTGGGTATACGTTTAGGCGTC/ TATAAAAACCAAACGCGCC \\
\hline UpF1/ UpR1 & TTAGTGGGTATATGTTTAGGTGTT/ TATAAAAACCAAACACACCTAA \\
\hline $\mathrm{WpF} 1 / \mathrm{WpR} 1$ & GTGGGCACACGCCCAGGCGCC/ TGTAAGGACCAGACGCGCC \\
\hline \multicolumn{2}{|c|}{ Deletion detection primer pairs } \\
\hline $1 F / R$ & AATTGAGTTACAGGCTTACTTGTGG/ TTGGTTTTGGTATAGGTCACAATCT \\
\hline $2 \mathrm{~F} / \mathrm{R}$ & TAGATGAGAAGAATTTTGGAACAGG/ CTCAATAAACCTGATGGCTACTTGT \\
\hline $3 \mathrm{~F} / \mathrm{R}$ & GAGCACATAACTTCGTTTTACGTTT/ TAATGGTCCATACAGGTGAAATCTT \\
\hline $4 \mathrm{~F} / \mathrm{R}$ & CTCTACAGTGGGTGAGGTTATGTCT/ TGGATAGTTTTCTTGGATACCACAT \\
\hline $5 \mathrm{~F} / \mathrm{R}$ & AGAGAGCTTAACTTTCGTTTTAGGC/ CATGAGGATGATTTCTCTGATTTCT \\
\hline $6 \mathrm{~F} / \mathrm{R}$ & GTGCTGTAGGGCATTCTACTGTATT/ ATTCATTTCCCCATCTCACATACTA \\
\hline $7 F / R$ & CACATCTGAAGACCTCTAGGAGAAG/ TCATGCTAGTGCTCTCTCTCAAATA \\
\hline $8 \mathrm{~F} / \mathrm{R}$ & ACTCTTCAAAACAAAACAAACCAAG/ TTTGGGATTTCATTCAATAAGTGAT \\
\hline $9 \mathrm{~F} / \mathrm{R}$ & GCAGCTTTTCTAGCTCATTTACACT/ ACAACACTATGAGGAATGTGTTTCA \\
\hline $10 \mathrm{~F} / \mathrm{R}$ & TGACCATCCTACAAAAGTACTGACA/ TCTAGGGTTGAGGTCTCCTTAGACT \\
\hline $11 \mathrm{~F} / \mathrm{R}$ & AAAGCAAAGAACTAGGAGAAAGAGG/ GTTTAAACCTCTGTTCCACAAAGAA \\
\hline $12 \mathrm{~F} / \mathrm{R}$ & ATTATGAAAAAGTGAAGCTTTGTGG/ GCCCTTCCTACCATGTCTATTTATT \\
\hline $13 \mathrm{~F} / \mathrm{R}$ & CTCTGGAAGAGTGAGAAGTAACAGG/ CTGGTGTTACTCAAGTTTCTCCATT \\
\hline $14 \mathrm{~F} / \mathrm{R}$ & AGTGAAAGAAGCCAGACACTAAAGA/ TTTAAATGTGGGTATCAAGGAAAAA \\
\hline $15 \mathrm{~F} / \mathrm{R}$ & CCTGGCAAGACTTAGTAAACACATT/ GACGTAAGTCTTTCTAATGCAGAGC \\
\hline $16 \mathrm{~F} / \mathrm{R}$ & CATCTAGGAGCTCATTAAAAATGGA/ AGAGGGGAGATACCTGCTAAATAGA \\
\hline $17 \mathrm{~F} / \mathrm{R}$ & ATGTAATAATTCCTGGAAGGGAGAC/ GGTTTATACAGATTGGATGATTTGC \\
\hline $18 \mathrm{~F} / \mathrm{R}$ & TTGTTGGGAAATCATAACAGATTTT/ ATTCCTGTATACTTCTGCCTGTGAC \\
\hline $19 \mathrm{~F} / \mathrm{R}$ & GGCAAAATCAAAGATGAATAAGCTA/ GCTCATGGTCAGTACACACTTTATG \\
\hline $20 \mathrm{~F} / \mathrm{R}$ & AACAACCGAAATGTTATTGATGGTG/ GTCGCCTGAAACAAATCTGCCACTTC \\
\hline
\end{tabular}

a) These primers contain restriction enzyme cutting sites for BamHI (TF5) and EcoRV (TF3), respectively.

analysis by using this antibody in order to evaluate expression of the Fhit protein in canine lymphoma cell lines. As shown in Fig. 1C, expression of the Fhit protein in all 5 cell lines was lower than that observed in PBMCs isolated from a healthy dog.

Methylation status of $C p G$ islands in canine lymphoma cell lines: The human $\mathrm{CpG}$-island profile was used to search for $\mathrm{CpG}$ islands around exon $1(-1,000$ to $+2,000 \mathrm{bp})$ of the canine FHIT gene. Canine $\mathrm{CpG}$ islands have been presumedly found at a 437-bp locus around canine FHIT exon $1(-126$ to +312$)$. Amplification of the methylated DNA by using the $\mathrm{MpF} 1 / \mathrm{MpR} 1$ primers did not yield any bands for any of the cell lines or the control PBMCs (Fig. 2A); in contrast, use of the primers UpF1/UpR1 yielded amplified unmethylated DNA from all the cell lines and the control PBMCs (Fig. 2B), suggesting that aberrant methylation could not have occurred in this region. Furthermore, amplification using the primers $\mathrm{WpF} 1 / \mathrm{WpR} 1$, which detect unmodified wild-type DNA, yielded faint bands in all the samples (Fig. 2C). However, the reduced level of PCR amplification by the $\mathrm{WpF} 1 / \mathrm{WpR} 1$ primers in comparison with the amplification by the $\mathrm{UpF} 1 / \mathrm{UpR} 1$ primers suggests that the DNA was at least partially modified by the CpGenome DNA Modification kit and that aberrant methylation

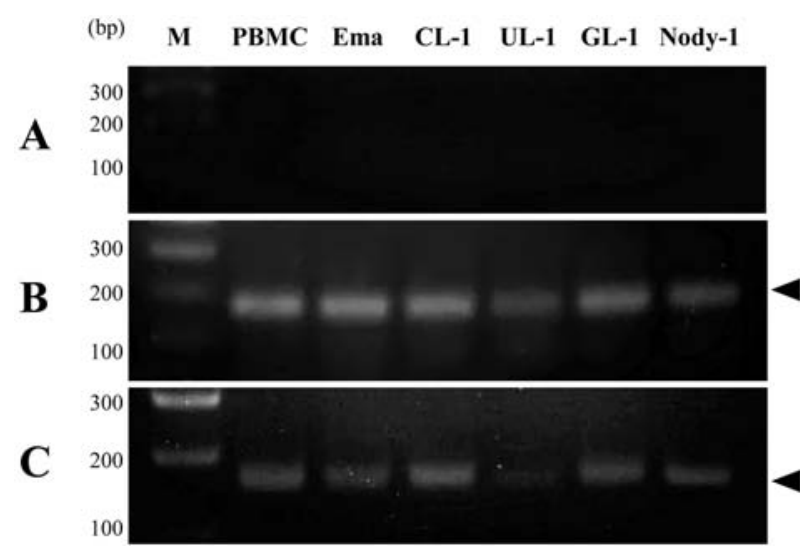

Fig. 2. Methylation-specific PCR (MS-PCR) analysis of canine lymphoma cell lines. DNA extracted from the 5 lymphoma cell lines and the PBMCs isolated from a healthy dog were subjected to bisulfite modification followed by PCR amplification using primers $\mathrm{MpF} 1 / \mathrm{MpR} 1$ (A) or UpF1/UpR1 (B), which amplify methylated FHIT DNA or unmethylated FHIT DNA, respectively. As a control, wild-type FHIT DNA, which had not undergone bisulfite modification, was also amplified by the primers $\mathrm{WpF} 1 / \mathrm{WpR} 1(\mathrm{C})$. 
had not occurred in any of the canine lymphoma cell lines.

Homozygous or heterozygous deletion of the FHIT locus in canine lymphoma cell lines: Homozygous or heterozygous deletion of the canine FHIT gene locus in canine lymphoma cell lines was evaluated by using 20 pairs of primers (Table 1). We did not detect any deletions between exons 3 and $3 \mathrm{~B}$ in the Ema, UL-1, GL-1 and Nody-1 cell lines. However, we did not detect any bands for the $6 \mathrm{~F} / \mathrm{R}$ amplified region in the CL-1 cell line, suggesting that a homozygous deletion had occurred (Fig. 3). This deletion was also detected in the midstream region between exons 4 and 5 (amplified by primers 18F/R), although amplified DNA was obtained from the downstream region, which was amplified by using the primers $19 \mathrm{~F} / \mathrm{R}$ (Fig. 3). In contrast, we did not detect any deletion in the other cell lines, except for that observed in the region amplified by using the primers $14 \mathrm{~F}$ / $\mathrm{R}$. In this region, amplification yielded a 1099-bp band in the control PBMCs, while an 830-bp band was detected in the Ema, Nody-1 and GL-1 cell lines (Fig. 3B). Furthermore, both of these bands were observed in the UL-1 cell line. Sequence analysis of the 830-bp band from the Ema cell line revealed that this region contained intermittent deletions consisting of a large deletion (200 bp), several small deletions (11, 3 and $2 \mathrm{bp}$ ) and 8 single-point mutations. Moreover, the 830-bp bands from the UL-1 and Ema cell lines had the same sequence. In contrast, the sequence of the 1099-bp band from the UL-1 cell line was identical to that of the PBMC samples.

\section{DISCUSSION}

In humans, decreased expression of Fhit protein has been observed in approximately $50 \%-83 \%$ of solid tumors and in $40 \%-76 \%$ of hematopoietic tumors $[2,13,16,26,39]$. Furthermore, a decrease in Fhit protein expression has been correlated with poor clinical prognosis of some human tumors,

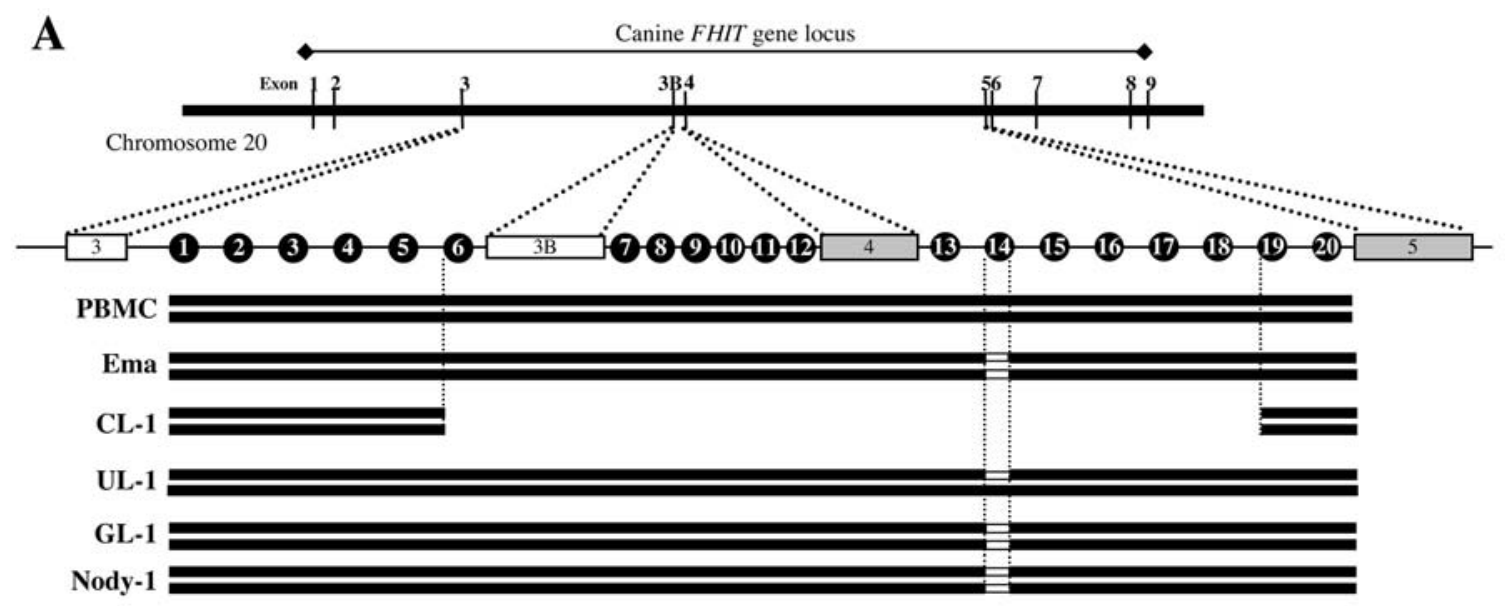

B
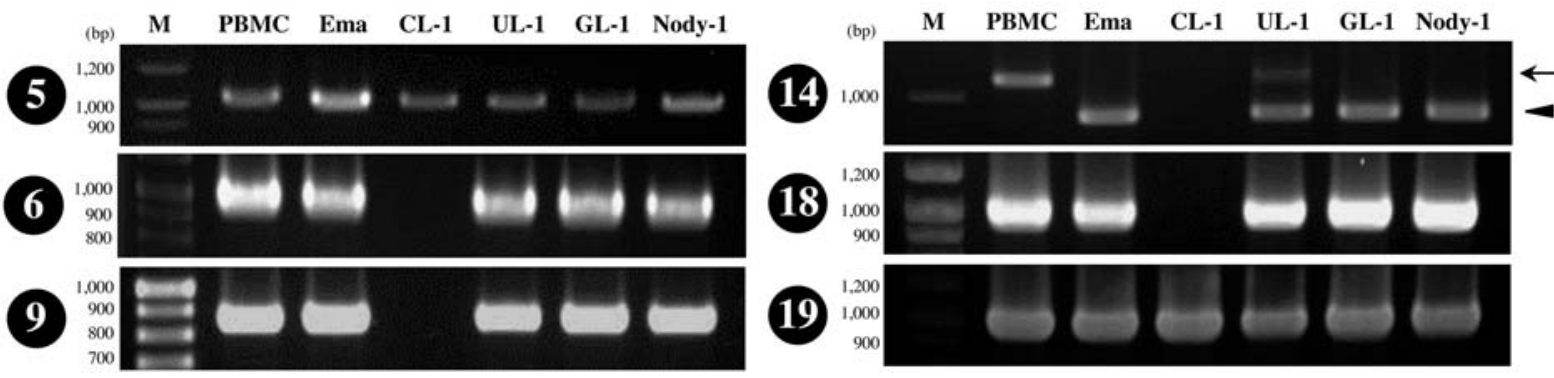

Fig. 3. A. Genomic deletions in the canine lymphoma cell lines. In order to identify the deletions of the canine FHIT genomic locus in the cell lines, we prepared 20 primer sets (shown in black circles) corresponding to the intronic region between exon 3 and the type Bspecific exon 3B (1-6), exon 3B and exon 4 (7-12) and exon 4 and exon 5 (13-20) on canine chromosome 20. The allelic information of the 5 lymphoma cell lines and the PBMCs isolated from a healthy dog is shown by black bars. The white bars shown at the 14th position represent intermittent deletions containing the 200-, 11-, 3- and 2- bp deletions (see text). B. Representative results of PCR analyses for detection of allelic information in the canine lymphoma cell lines. The DNA samples from the normal control PBMCs and the 5 lymphoma cell lines were subjected to PCR amplification to identify homozygous or heterozygous deletions. Each black circle with a white number represents an amplified region. In the 14th position, we observed an expected band (an arrow) and a smaller band (an arrowhead), and sequencing analysis was used to confirm that the latter band resulted from intermittent deletions containing 200-, 11-, 3- and 2-bp. 
including lung, oral and breast cancers $[4,12,31]$. In the present study, Fhit protein expression decreased in all the canine lymphoma cell lines examined, suggesting that decreased expression of the Fhit protein may be associated with tumorigenesis in canine lymphoma.

It has been suggested that the FHIT gene and its protein play an important role in tumorigenesis in human tumors. Indeed, it has been reported that Fhit-deficient mice develop spontaneous or N-nitromethylbenzylamine (NMBA)induced tumors more frequently than mice with normal expression of Fhit $[7,38]$. Nevertheless, the precise function of the Fhit protein has not been clarified. However, some studies have revealed that Fhit modulates the mid-S phase DNA checkpoint response by regulating the checkpoint proteins Hus1 and phosphoChk1 [19, 20]. Other studies have described that Fhit suppresses target genes such as cyclin D1, axin2, Mmp-14 and survivin by directly binding to $\beta$-catenin [34].

Aberrant FHIT transcripts lacking regions between exons 3-9 have been detected in human hematopoietic malignancies [13, 21, 26, 29], although the wild-type transcript is also expressed along with these transcripts [13, 21, 26, 29]. In contrast, complete loss of FHIT transcripts is detected infrequently $[13,21,26,29]$; nevertheless, Fhit protein is frequently absent in these tumor cells $[13,26]$. In this study, we observed that expression of the wild-type FHIT transcript was reduced in 2 canine lymphoma lines (UL-1 and GL-1) and absent in the other 2 lines (Ema and Nody-1) [Fig. 1B (a)]. Moreover, the expression of the ORF region decreased in all the cell lines, and the FHIT ORF expression was completely absent in CL-1 [Fig. 1B (c)]. We detected a homozygous deletion between the midstream region of intron 3 and the region before exon 5 of the FHIT gene locus in the CL-1 cell line (Fig. 3). Furthermore, in the RT-PCR analysis using the e1/eL primers, we obtained approximately 500-bp- and 600-bp-long aberrant FHIT transcripts from the CL-1 cDNA [Fig. 1B (a)]. These findings suggested that the aberrant transcripts of the CL-1 cell line might have resulted from the absence of exon 4 in the FHIT cDNA. In order to clarify the deletion in the CL-1 cDNA, we performed RT-PCR amplification of the cDNA between exons 1 and 5 by using the el primer along with a newly designed antisense primer. We selected 3 amplified bands with different sizes and performed direct sequencing analysis. A complete sequence was obtained in 1 of the 3 sequence reactions, while the sequences could not determined in the other 2 reactions. This sequence was shown to be 135 bp shorter than the wild-type FHIT transcript. In this sequence, the 3 ' end of exon 2 was connected to a 58-bp sequence that was located between intron 4 of the FHIT gene locus, followed by the 5' initiation site of exon 5 (Fig. 3A). Although the results of PCR analysis of the FHIT gene locus (data not shown) confirmed the existence of exon 3 on the CL- 1 genome, exons 3 and 4 were absent from the CL-1 cDNA. Moreover, we detected a reduction (or absence) of Fhit protein expression in the CL-1 cell line (Fig. 1C). Homozygous or heterozygous deletion, which results in loss of the Fhit protein if the deletion contains the ORF region, of the FHIT gene locus has also been reported in many types of human cancer cells [18]. These data suggest that the reduction (or absence) of Fhit protein expression in CL-1 cells can be attributed to the absence of exon 4, which contains the start codon of the ORF, and that homozygous deletion of the FHIT gene is also associated with tumorigenesis in canine lymphoma.

It has recently been shown that an alternative splicing form-the type-B FHIT transcript-is coexpressed with the wild-type FHIT transcript in the PBMCs, spleen and intestine of healthy dogs and that it may play a role in an alternative Fhit-protein-expressing system that is activated when expression of the wild-type transcript is reduced [15]. In this study, the type-B transcript could not be detected in any of the canine lymphoma cell lines. Exon 3B, which is a specific exon for the type-B transcript, was identified in the genome of all the cell lines, except for CL-1. These observations suggest that expression of the type-B transcript is induced in normal cells but not in canine lymphoma cell lines.

In the Ema and Nody-1 cell lines, the wild-type transcript could not be amplified, but the ORF region was expressed weakly. In contrast, the wild-type transcript was weakly expressed in the UL-1 and GL-1 cell lines, which certainly contained the ORF region. We had confirmed that all the cell lines contained exons 1,2 and 3 in their genome and exons 6 through 9 in their cDNA (data not shown); therefore, the abovementioned observation may have resulted from incomplete cDNA synthesis during the RT reaction in these cell lines. Alternatively, it could have resulted from the existence of an alternative splicing form(s) other than type B in these lines. Further studies are necessary to clarify these observations.

In humans, aberrant methylation of 5' $\mathrm{CpG}$ islands in the FHIT gene has been reported in some solid tumors, including esophageal, cervical, lung and breast cancers and in hematopoietic malignancies, showing that methylation causes reductions in the expression levels of the FHIT gene and Fhit protein $[30,33,39,40]$. The 5' $\mathrm{CpG}$ island of the human FHIT gene is located in a 460-bp region around exon 1 (from -95 to $+365 \mathrm{bp}$ ) [30]; however, the 5' $\mathrm{CpG}$ island of the canine FHIT gene has not been explored previously. Human 5' CpG islands have been detected using the following criteria [30]: GC content, 66.5\%; CpG density, 7.8\%; and observed/expected $\mathrm{CpG}$ index, 0.7. We used these criteria to identify 5 , $\mathrm{CpG}$ islands in the region around exon 1 , ranging from $-1,000$ to $+2,000 \mathrm{bp}$, of the canine FHIT gene. A presumed canine $\mathrm{CpG}$ island, which was shown to have a GC content of $65.98 \%$ and $\mathrm{CpG}$ density of $6.64 \%$, was detected in a 437-bp region around canine FHIT gene exon $1(-126$ to +312$)$. In the present study, we designed sense and antisense primers corresponding to this region. While aberrant methylation could not be detected by using these primers, the Fhit protein expression level was decreased in all the canine lymphoma cell lines examined. In human tumors, it has been reported that a primer set designed to 
detect 5' CpG-island methylation of the FHIT gene in esophageal cancer could not detect it in lung and breast cancers $[30,40]$. Furthermore, murine FHIT gene analysis has revealed the presence of cancer- or tissue-specific methylation patterns [14]. In the present study, we could not detect aberrant methylation in any of the cell lines; however, further studies are necessary to conclude that there is no relationship between the 5' CpG-island methylation status and the Fhit protein expression level in canine lymphoma cell lines.

In this study, we identified widespread genomic deletions that contained the ORF region in the CL-1 cell line and homozygous (Ema, GL-1 and Nody-1 cell lines) and heterozygous deletions (UL-1 cell line) in intron 4 of the canine FHIT genomic sequence. Sequence analysis revealed that the heterozygous deletion pattern had intermittent deletions consisting of a large deletion (200 bp) and 3 small deletions (46, 3 and $2 \mathrm{bp}$ ). In humans, the tumor-specific deletion around exon 5 of the FHIT gene, spanning the region between exon 4 and the proximal 50-kbp region of intron 5 , has been well described $[6,18]$. Human exon 5 corresponds to canine exon 4 , which contains the initiation site of the ORF in the canine FHIT gene [15]. The identified deletion point of the canine FHIT gene is located in the proximal $37-$ kbp region of canine FHIT intron 4, which corresponds to the human FHIT deletion site. However, this aberration of canine FHIT intron 4 has no apparent effect on the ORF of the FHIT gene. Further analysis is necessary to clarify the relationship between this deletion and the expression of the FHIT gene and/or the Fhit protein.

In this study, we have shown that the reduction in Fhit protein expression in the 5 canine lymphoma cell lines was similar to that observed in human tumor cells. The FHIT gene aberrations that resulted in expression of the aberrant FHIT transcripts were detected in the CL-1 cell line, but were not observed in the other cell lines. Expression of the wild-type FHIT transcript seemed to be reduced in all the cell lines; however, we could not confirm the involvement of aberrant methylation events in the 5' $\mathrm{CpG}$ island of the canine FHIT gene. However, we were able to identify homozygous or heterozygous deletions in the canine FHIT genome in all the canine lymphoma cell lines, suggesting that the canine FHIT gene locus is also a fragile site in the genomes of lymphoma cells.

In human lymphocytic malignancies, the incidence of loss (decrease) of wild-type FHIT gene transcripts and coexpression of aberrant FHIT gene transcripts have been reported to be approximately $37 \%-46 \%$ and $27 \%-80 \%$, respectively $[5,21,26,36]$, and the incidence of reduction or absence of Fhit protein expression has been shown to be approximately $58 \%-76 \%[2,5,13]$. Moreover, hypermethylation of the FHIT promoter region has been reported in $40 \%$ of acute lymphoblastic (ALL) leukemia cell lines and $27 \%$ of pediatric ALL patients $[37,39]$, and allelic loss of the FHIT gene locus has been described in chronic lymphocytic leukemia [10]. In the present study, we detected decreased expression of wild-type FHIT transcripts and concurrent expression of aberrant FHIT transcripts in canine lymphoma cell lines; we also observed decreased expression of the Fhit protein in all the cell lines. While aberrant hypermethylation of the canine FHIT 5, $\mathrm{CpG}$ island could not be detected in all the cell lines, we did detect some homozygous or heterozygous deletions of the canine FHIT gene locus in them. Therefore, the decreased expression level of the canine FHIT gene and the Fhit protein might be an important factor in tumorigenesis in canine lymphoma in a manner similar to that observed in the case of human hematopoietic tumors. The molecular mechanism of tumorigenesis in dog tumors has not been completely clarified. Further studies using clinical tumor specimens are necessary to identify the relationship between aberrations of the FHIT gene and tumorigenesis in dogs.

ACKNOWLEDGEMENTS. This research was supported by a grant-in-aid from the Ministry of Education, Culture, Sports, Science and Technology of Japan (19390416). The authors would like to acknowledge the technical expertise of the DNA Core Facility of the Center for Gene Research, Yamaguchi University.

\section{REFERENCES}

1. Ahmadian, M., Wistuba, I. I., Fong, K. M., Behrens, C., Kodagoda, D. R., Saboorian, M. H., Shay, J., Tomlinson, G. E., Blum, J., Minna, J. D. and Gazdar, A. F. 1997. Analysis of the FHIT gene and FRA3B region in sporadic breast cancer, preneoplastic lesions, and familial breast cancer probands. Cancer Res. 57: 3664-3668.

2. Albitar, M., Manshouri, T., Gidel, C., Croce, C., Kornblau, S., Pierce, S. and Kantarjian, H. M. 2001. Clinical significance of fragile histidine triad gene expression in adult acute lymphoblastic leukemia. Leuk. Res. 25: 859-864.

3. Arlt, M. F., Durkin, S. G., Ragland, R. L. and Glover, T. W. 2006. Common fragile sites as targets for chromosome rearrangements. DNA Repair 5: 1126-1135.

4. Arun, B., Kilic, G., Yen, C., Foster, B., Yardley, D. A., Gaynor, R. and Ashfaq, R. 2005. Loss of FHIT expression in breast cancer is correlated with poor prognostic markers. Cancer Epidemiol. Biomarkers Prev. 14: 1681-1685.

5. Chen, P. M., Yang, M. H., Hsiao, L. T., Yu, I. T., Chu, C. J., Chao, T. C., Yen, C. C., Wang, W. S., Chiou T. J. and Liu, J. H. 2004. Decreased FHIT protein expression correlates with a worse prognosis in patients with diffuse large B-cell lymphoma. Oncol. Rep. 11: 349-356.

6. Corbin, S., Neilly, M. E., Espinosa R. III, Davis, E. M., McKeithan, T. W. and Le Beau, M. M. 2002. Identification of unstable sequences within the common fragile site at 3 p14.2: implications for the mechanism of deletions within fragile histidine triad gene/ common fragile site at 3 p14.2 in tumors. Cancer Res. 62: 3477-3484.

7. Fong, L. Y., Fidanza, V., Zanesi, N., Lock, L. F., Siracusa, L. D., Mancini, R., Siprashvili, Z., Ottey, M., Martin, S. E., Druck, T., McCue, P. A., Croce, C. M. and Huebner, K. 2000. Muir-Torre-like syndrome in Fhit-deficient mice. Proc. Natl. Acad. Sci. U.S.A. 97: 4742-4747.

8. Fong, K. M., Biesterveld, E. J., Virmani, A., Wistuba, I., Sekido, Y., Bader, S. A., Ahmadian, M., Ong, S. T., Rassool, 
F. V., Zimmerman, P. V., Giaccone, G., Gazdar, A. F. and Minna, J. D. 1997. FHIT and FRA3B 3p14.2 allele loss are common in lung cancer and preneoplastic bronchial legions and are associated with cancer-related FHIT cDNA splicing aberrations. Cancer Res. 57: 2256-2267.

9. Fosmire, S. P., Thomas, R., Jubala, C. M., Wojcieszyn, J. W., Valli, V. E., Getzy, D. M., Smith, T. L., Gardner, L. A., Ritt, M. G., Bell, J. S., Freeman, K. P., Greenfield, B. E., Lana, S. E., Kisseberth, W. C., Helfand, S. C., Cutter, G. R., Breen, M. and Modiano, J. F. Inactivation of the p16 cyclin-dependent kinase inhibitor in high-grade canine non-Hodgkin's T-cell lymphoma. 2007. Vet. Pathol. 44: 467-478.

10. Gartenhaus, R. B. 1997. Allelic loss determination in chronic lymphocytic leukemia by immunomagnetic bead sorting and microsatellite marker analysis. Oncogene 14: 375-378.

11. Glover, T. W. 2006. Common fragile sites. Cancer Lett. 232: 4-12.

12. Guerin, L. A., Hoffman, H. T., Zimmerman, M. B. and Robinson, R. A. 2006. Decreased fragile histidine triad gene protein expression is associated with worse prognosis in oral squamous carcinoma. Arch. Pathol. Lab. Med. 130: 158-164.

13. Hallas, C., Albitar, M., Letofsky, J., Keating, M. J., Huebner, K. and Croce, C. M. 1999. Loss of FHIT expression in acute lymphoblastic leukemia. Clin. Cancer Res. 5: 2409-2414.

14. Han, S. Y., Iliopoulos, D., Druck, T., Guler, G., Grubbs, C. J., Pereira, M., Zhang, Z., You, M., Lubet, R. A., Fong, L. Y. and Huebner, K. 2004. CpG methylation in the Fhit regulatory region: relation to Fhit expression in murine tumors. Oncogene 23: 3990-3998.

15. Hiraoka, H., Minami, K., Kaneko, N., Miyama-shimokawa, T., Mizuno, T. and Okuda, M. Molecular cloning of the canine fragile histidine triad (FHIT) gene and Fhit protein expression in canine peripheral blood mononuclear cells. J. Vet. Med. Sci. (in press).

16. Huebner, K. and Croce, C. M. 2003. Cancer and the FRA3B/ FHIT fragile locus: it's a HIT. Br. J. Cancer 88: 1501-1506.

17. Iliopoulos, D., Guler, G., Han, S. Y., Druck, T., Ottey, M., McCorkell, K. A. and Huebner, K. 2006. Roles of FHIT and WWOX fragile genes in cancer. Cancer Lett. 232: 27-36.

18. Inoue, H., Ishii, H., Alder, H., Snyder, E., Druck, T., Huebner, K. and Croce, C. M. 1997. Sequence of the FRA3B common fragile region: implications for the mechanism of FHIT deletion. Proc. Natl. Acad. Sci. U.S.A. 94: 14584-14589.

19. Ishii, H., Wang, Y. and Huebner, K. 2007. A Fhit-ing role in the DNA checkpoint response. Cell Cycle 6: 1044-1048.

20. Ishii, H., Mimori, K., Inoue, H., Inageta, T., Ishikawa, K., Semba, S., Druck, T., Trapasso, F., Tani, K., Vecchione, A., Croce, C. M., Mori, M. and Huebner, K. 2006. Fhit modulates the DNA damage checkpoint response. Cancer Res. 66: 11287-11292.

21. Iwai, T., Yokota, S., Nakao, M., Nakazawa, N., Taniwaki, M., Kimura, T., Sonoda, Y., Kaneko, H., Okuda, T., Azuma, H., Oka, T., Takeda, T., Watanabe, A., Kikuta, A., Asami, K., Sekine, I., Matsushita, T., Tsuchiya, T., Mimaya, J., Koizumi, S., Ohata, S., Miyake, M., Takaue, Y., Iwai, A., Nishikawa, K., Matsumoto, K., Kawakami, K., Hyakuna, N. and Fujimoto, T. 1998. Frequent aberration of FHIT gene expression in acute leukemias. Cancer Res. 58: 5182-5187.

22. Larson, A. A., Kern, E., Curtiss, S., Gordon, R., Cavenee, W. K. and Hampton, G. M. 1997. High resolution analysis of chromosome $3 p$ alterations in cervical carcinoma. Cancer Res. 57: 4082-4090.

23. Momoi, Y., Okai, Y., Watari, T., Goitsuka, R., Tsujimoto, H. and Hasegawa, A. 1997. Establishment and characterization of a canine T-lymphoblastid cell line derived from malignant lymphoma. Vet. Immnol. Immunophol. 59: 11-20.

24. Nakaichi, M., Taura, Y., Kanki, M, Mamba, K., Momoi, Y., Tsujimoto, H. and Nakama, S. 1996. Establishment and characterization of a new canine B-cell leukemia cell line. J. Vet. Med. Sci. 58: 469-471.

25. Peters, I. R., Peeters, D., Helps, C. R. and Day, M. J. 2007. Development and application of multiple internal reference (housekeeper) gene assays for accurate normalization of canine gene expression studies. Vet. Immunol. Immunopathol. 117: $55-66$.

26. Peters, U. R., Hasse U., Opplinger, E., Tschan, M., Ong, S. T., Rassool, F. V., Borisch, B., Tobler, A. and Fey, M. F. 1999. Aberrant FHIT mRNA transcripts are present in malignant and normal haematopoiesis, but absence of FHIT protein is restricted to leukemia. Oncogene 18: 79-85.

27. Shridhar, R., Shridhar, V., Wang, X., Paradee, W., Dugan, M., Sarkar, F., Wilke, C., Glover, T. W., Vaitkevicius, V. K. and Smith, D. I. 1996. Frequent breakpoints in the 3p14.2 fragile site, FRA3B, in pancreatic tumors. Cancer Res. 56: 434-4350.

28. Smith, D. I., McAvoy, S., Zhu, Y. and Perez, D. S. 2007. Large common fragile site genes and cancer. Semin. Cancer Biol. 17: $31-41$.

29. Sugimoto, K., Yamada, K., Miyagawa, K., Hirai, H., Oshimi, K. 1997. Decreased or altered expression of the FHIT gene in human leukemias. Stem Cells 15: 223-228.

30. Tanaka, H., Shimada, Y., Harada, H., Shinoda, M., Hatooka, S., Imamura, M. and Ishizaki, K. 1998. Methylation of the 5' $\mathrm{CpG}$ island of the FHIT gene is closely associated with transcriptional inactivation in esophageal squamous cell carcinomas. Cancer Res. 58: 3429-3434.

31. Toledo, G., Sola, J. J., Lozano, M. D., Soria, E. and Pardo, J. 2004. Loss of FHIT protein expression is related to high proliferation, low apoptosis and worse prognosis in non-small-cell lung cancer. Mod. Pathol. 17: 440-448.

32. Vail, D. M. and Young, K. M. 2007. Canine lymphoma and lymphoid leukemia. pp. 699-733. In: Small Animal Clinical Oncology, 4th ed. (Withrow, S. J. and Vail, D. M. eds.), Saunders, Philadelphia.

33. Virmani, A. K., Muller, C., Rathi, A., Zoechbauer-Mueller, S., Mathis, M. and Gazdar, A. F. 2001. Aberrant methylation during cervical carcinogenesis. Clin. Cancer Res. 7: 584-589.

34. Weiske, J., Albring, K. F. and Huber, O. 2007. The tumor suppressor Fhit acts as a repressor of $\beta$-catenin transcriptional activity. Proc. Natl. Acad. Sci. U.S.A. 104: 20344-20349.

35. Yamazaki, J., Baba, K., Goto-Koshino, Y., Setoguchi-Mukai, A, Fujino, Y., Ohno, K. and Tsujimoto, H. 2008. Quantitative assessment of minimal residual disease (MRD) in canine lymphoma by using real-time polymerase chain reaction. Vet. Immunol. Immunopathol. 126: 321-331.

36. Yang, H. W., Piao, H. Y., Taki, T., Chen, T., Hashizume, K., Ohnishi, H., Bessho, F., Yanagisawa, M., Matsuo, Y. and Hayashi, Y. 1999. Pattern of FHIT gene expression in normal and leukaemic cells. Int. J. Cancer 81: 897-901.

37. Yang, Y., Takeuchi, S., Hofmann, W. K., Ikezoe, T., van Dongen, J. J., Szczepański, T., Bartram, C. R., Yoshino, N., Taguchi, H. and Koeffler, H. P. 2006. Aberrant methylation in promoter-associated $\mathrm{CpG}$ islands of multiple genes in acute lymphoblastic leukemia. Leuk. Res. 30: 98-102.

38. Zanesi, N., Fidanza,V., Fong, L. Y., Mancini, R., Druck, T., Valtieri, M., Rüdiger, T., McCue, P. A., Croce, C. M. and Huebner, K. 2001. The tumor spectrum in FHIT-deficient 
mice. Proc. Natl. Acad. Sci. U.S.A. 98: 10250-10255.

39. Zheng, S., Ma, X., Zhang, L., Gunn, L., Smith, M. T., Wiemels, J. L., Leung, K., Buffler, P. A. and Wiencke, J. K. 2004. Hypermethylation of the $5 \mathrm{CpG}$ island of the FHIT gene is associated with hyperdiploid and translocation-negative subtypes of pediatric leukemia. Cancer Res. 64: 2000-2006.
40. Zöchbauer-Müller, S., Fong, K. M., Maitra, A., Lam, S., Geradts, J., Ashfaq, R., Virmani, A. K., Milchgrub, S., Gazdae, A. F. and Minna, J. D. 2001. 5 CpG island methylation of the FHIT gene is correlated with loss of gene expression in lung and breast cancer. Cancer Res. 61: 3581-3585. 